\title{
Testing Developmental Pathways to Antisocial Personality Problems
}

\author{
Sofia Diamantopoulou • Frank C. Verhulst • \\ Jan van der Ende
}

Published online: 18 August 2009

(C) The Author(s) 2009. This article is published with open access at Springerlink.com

\begin{abstract}
This study examined the development of antisocial personality problems (APP) in young adulthood from disruptive behaviors and internalizing problems in childhood and adolescence. Parent ratings of 507 children's (aged 6-8 years) symptoms of attention deficit hyperactivity disorder, oppositional defiant disorder, and anxiety, were linked to self-ratings of adolescents' (aged 14-16 years) symptoms of depression, substance use, conduct problems, and somatic problems, to predict self-ratings of APP in young adulthood (age 20-22 years). The findings suggested a hierarchical development of antisocial behavior problems. Despite being positively associated with conduct problems in adolescence, neither internalizing problems nor substance use added to the prediction of APP in young adulthood from conduct problems in adolescence. The developmental pathways to APP in young adulthood did not differ by gender.
\end{abstract}

Keywords Developmental pathways · Antisocial personality problems · Disruptive behavior problems · Internalizing problems $\cdot$ Longitudinal study

Persistent antisocial behavior in adulthood is associated with a range of problematic behaviors and outcomes including violent and criminal behavior, substance use, unemployment, divorce, and early death (Black et al. 1996; Dolan and Coid 1993; Hodgins and Cote 1993; Westermeyer and Thuras 2005). It is estimated that over half of all male prisoners in Europe and North America fulfill the diagnostic criteria for antisocial personality

S. Diamantopoulou $(\bowtie) \cdot$ F. C. Verhulst $\cdot$ J. van der Ende Department of Child and Adolescent Psychiatry,

Erasmus MC-Sophia Children's Hospital,

P.O. Box 2060, 3000 CB Rotterdam, The Netherlands

e-mail: s.diamantopoulou@erasmusmc.nl disorder (APD; Moran 1999). Because of the poor prognosis and poor treatment response for APD (Dolan and Coid 1993), identifying childhood predictors of later APD is critical for prevention. This study examined a theoretical model (Loeber et al. 2000) linking behavioral and emotional problems in childhood and adolescence with antisocial personality problems in early adulthood.

Follow-up studies of clinical and population-based samples show that the factor most often associated with the development of APD is conduct disorder (CD) or serious conduct problems in childhood and adolescence (e.g., Abramowitz et al. 2004; Copeland et al. 2007; Hill 2003; Kim-Cohen et al. 2003; Kratzer and Hodgins 1997; Salekin et al. 2004; Washburn et al. 2007). The presence of $\mathrm{CD}$ in adolescence is also an important prerequisite for the diagnosis of APD in the DSM-IV (American Psychiatric Association 1994). Although the continuity of antisocial behavior across developmental periods is well established, the literature is limited in several important ways.

First, many longitudinal studies linking CD with APD start in adolescence (e.g., Loeber et al. 2002; Salekin et al. 2004) so that factors influencing the development of antisocial behaviors prior to adolescence are poorly understood. A common shortcoming of studies that have examined childhood factors related to adult APD is that they have utilized a categorical measurement approach assigning individuals to diagnostic classes (e.g., Fergusson et al. 2005; Kim-Cohen et al. 2003; Lahey et al. 2005). A problem with this approach is that variation in severity and dysfunction among individuals falling below and above cut-off is lost (Hinshaw et al. 1993). Second, reliance on $\mathrm{CD}$ alone to predict APD has been found to result in a substantial number of false-positive predictions (Lahey et al. 2005; Maughan and Rutter 2001; Storm-Mathisen and Vaglum 1994), whereas recent findings suggest that, in 
particular, the combination of externalizing and internalizing problems in adolescence predicts more serious antisocial outcomes than conduct problems alone (e.g., Fombonne et al. 2001; Sourander et al. 2007). Hence, a systematic, longitudinal investigation starting in early childhood, that examines behavioral and affective factors associated with adult antisocial personality problems utilizing a dimensional approach, could clarify the prodromal states of adult antisocial personality problems.

Based on a literature review, Loeber et al. (2000) suggested a theoretical model describing the development of APD as a culmination of a gradual hierarchical unfolding of disruptive behaviors and internalizing problems in childhood and adolescence. According to this model, conduct problems in adolescence is regarded as the factor setting the stage for the development of adult APD. However, the development of $\mathrm{CD}$ is influenced both by previous levels of disruptive behaviors in childhood and by co-occurring affective and behavioral problems in adolescence. Below follows a description of this model (see Fig. 1) starting first with a description of antecedents of antisocial behavior in early childhood and followed by a description of co-occurring problems influencing the development of conduct problems in adolescence.

In terms of antecedents of antisocial behavior, $\mathrm{CD}$ in adolescence appears to emerge from milder forms of disruptive behaviors in childhood, that is, oppositional defiant disorder (ODD) and attention deficit hyperactivity disorder (ADHD; see also: Loeber et al. 2003). ADHD, ODD, and $\mathrm{CD}$, have been found to co-occur at greater than chance levels in cross-sectional studies (e.g., Angold et al. 1999; Willcutt et al. 1999). The developmental progression from ODD to CD has been confirmed by several prospective longitudinal studies (for a review see Burke et al. 2002). However, whereas some findings suggest a direct link between ADHD in childhood and CD in adolescence (e.g., Mannuzza et al. 1993; Monuteaux et al. 2007), other findings suggest that ADHD in childhood leads to CD in adolescence only when ODD symptoms are initially also present (e.g., Lahey et al. 2000; Whittinger et al. 2007). In line with the above, the model suggests that the relation between ADHD in childhood and CD in adolescence is primarily mediated by childhood ODD, but symptoms of ADHD may also have a direct effect on the development, and increase the severity, of conduct problems in adolescence (illustrated by a dotted arrow in Fig. 1).

The model further suggests that anxiety in childhood also plays a significant role in the development of antisocial behavior. However previous studies on the issue have produced mixed results. On the one hand, anxiety, mainly through its relation with behavioral inhibition, has been found to buffer the development of antisocial behavior (Kerr et al. 1997). On the other hand, anxiety and disruptive behavior problems have been found to be highly comorbid (Angold et al. 1999; Costello et al. 2003) and comorbid conduct and anxiety problems have been found to predict more severe psychosocial outcome (Sourander et al. 2007). Moreover, some findings suggest that anxiety precedes the development of depression (Burke et al. 2005; de Graaf et al. 2003), which in turn, is believed to increase antisocial behaviors (see further below). Hence, in the model, the influence of anxiety on the development of antisocial behavior is not explicitly specified and is therefore indicated by a non-directional line between anxiety and depression. Nevertheless, given that the model describes associations between constructs in time, this non-directional line can be interpreted as a direct effect of anxiety on depression.

In terms of co-occurring affective problems influencing the development of antisocial behavior in adolescence, the model suggests that both depression and somatoform disorder are positively associated with $\mathrm{CD}$. Depressive symptoms and CD often co-occur (Angold et al. 1999; Costello et al. 2003) and the few studies conducted on the issue suggest a positive association between $\mathrm{CD}$ and somatic problems (Lilienfeld 1992; Sourander et al. 2005). It has been suggested that symptoms of depression such as irritability or hopelessness may increase levels of antisocial behavior by reducing concern for the consequences of antisocial behavior and fueling interpersonal conflict (Kasen et al. 2001). Nevertheless, because studies on the temporal relations between conduct problems and depression have produced mixed results, with some findings suggesting that CD precedes depression (e.g., Biederman et al. 1995; Nock et al. 2006), and other findings suggesting that depression precedes CD (e.g., Kovacs et al. 1988), the relation between the two constructs is assumed to be reciprocal in the model (illustrated by a double-headed arrow in Fig. 1). Given the limited examination of the relation between $\mathrm{CD}$ and somatoform disorder in adolescence, the model does not make inferences about the direction of the relation between the two constructs (illustrated by a line without arrowhead in Fig. 1).

With regards to other associated problems influencing the development of antisocial behavior, the model suggests a reciprocal association between $\mathrm{CD}$ and substance use. Most adolescents with CD misuse alcohol and/or illicit drugs (Armstrong and Costello 2002). However, whereas some view substance use as an outcome of CD (e.g., Rhee and Waldman 2002), others suggest that substance use may increase antisocial behavior in youths by increasing exposure to deviant peers and by impairing decisionmaking (Loeber et al. 2002, 2003). Because of the above, and also because substance use has been shown to be related both to depression (e.g., de Graaf et al. 2003) and to disruptive behavior disorders (Loeber et al. 2000), the 
Early Childhood $\longrightarrow$ Adolescence $\longrightarrow$ Young Adulthood

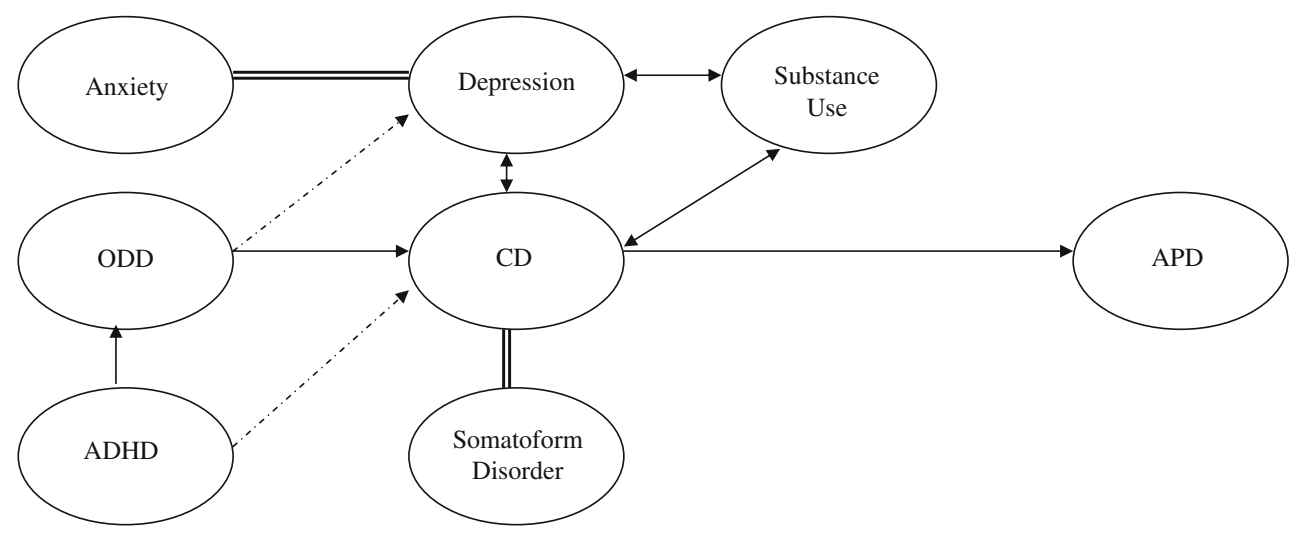

Fig. 1 Conceptual model linking disruptive behavior problems and co-occurring problems in childhood and adolescence with antisocial personality disorder (APD) in young adulthood (adapted from Loeber et al. 2000). Dotted arrows indicate that symptoms of oppositional defiant disorder (ODD) set the stage for internalizing problems and

model suggests reciprocal associations between the three constructs (illustrated in Fig. 1 with double-headed arrows).

In sum, according to the theoretical model suggested by Loeber et al. (2000) APD or antisocial personality problems (APP) in adulthood comprise the culmination of combined behavioral and affective problems that can be traced back to adolescence and early childhood. To our knowledge, this theoretical model has not yet been empirically tested. Hence, the primary aim of the present study was to examine how well the proposed theoretical model predicted APP in young adulthood, in a large, community-based sample assessed in early childhood, adolescence, and emerging adulthood. Although the model describes the development of antisocial behavior in terms of clinical diagnoses (e.g., CD and APD), in this study, we tested how well the model would describe the development of antisocial behaviors measured as continuous variables in the general population. Another important difference between the model suggested by Loeber and colleagues and the model we tested is that we tested the model's dotted paths (see Fig. 1) as direct paths, that is, we examined the direct effects of ODD symptoms in early childhood on depression in adolescence and we also examined the direct effects of ADHD symptoms in early childhood on CD symptoms in adolescence. As a second aim, we also compared the above theoretical model with an alternative model including direct associations between internalizing problems and substance use in adolescence and APP in young adulthood. What motivated the examination of this alternative model was that, as already stated above, previous findings suggest that comorbid conduct and internalizing problems in adolescence predict more serious antisocial outcomes than conduct problems alone that, symptoms of attention deficit hyperactivity disorder (ADHD), in the presence of ODD symptoms, may worsen the severity of conduct disorder (CD). Lines without arrowheads indicate that the relation between the constructs is not clear. Note that, despite its position in the figure, substance use is measured in adolescence

(Fombonne et al., Sourander et al. 2007), whereas substance use among youths with $\mathrm{CD}$ has been found to increase the odds for developing APD (Loeber et al. 2002; Washburn et al. 2007). Finally, we controlled for the effects of socioeconomic status given that it has been found to be a robust predictor of children's conduct problems (e.g., D'Onofrio et al. 2009).

A final issue investigated in the present study was the extent to which the development of APP varies by gender. Although it is well documented that conduct problems and antisocial behavior in general tend to be more frequent in males than in females (e.g., Kim-Cohen et al. 2003; Washburn et al. 2007), a growing number of studies show that the long-term consequences of conduct problems are nonetheless very similar for both males and females (e.g., Fergusson and Horwood 1998; Moffitt et al. 2001). However, the concurrent correlates of CD symptoms appear to differ by gender, CD symptoms being less often associated with ADHD symptoms (Moffitt et al. 2001) and more often associated with depression in girls than in boys (Costello et al. 2003; but see: Maughan et al. 2004, reporting opposite results). Moreover, a female-specific pathway for the development of APD has been suggested with stronger associations between adolescent conduct problems and adult APD for females than for males and with more females than males starting to exhibit antisocial behaviors in adolescence without displaying childhood disruptive behavior problems (Silverthorn and Frick 1999). Based on the above, we expected that girls compared to boys would show weaker associations between disruptive behavior problems in early childhood and $\mathrm{CD}$ symptoms in adolescence, and stronger associations between CD symptoms and internalizing problems in adoles- 
cence and between CD symptoms and APP in young adulthood.

\section{Method}

Participants and Procedure

This study is based on data from the Zuid-Holland longitudinal study, a seven-wave longitudinal study of behavioral and emotional problems in children that started in 1983 (for details of the initial data collection see: Verhulst et al. 1985). The original sample of 2,600 children from 13 birth cohorts aged 4 to 16 was drawn from municipal registers that list all residents in the Dutch province of Zuid-Holland. A random sample of 100 children of each gender and age of Dutch nationality was drawn. Of the 2,447 parents reached, 2,076 (i.e., 84.8\%) provided usable data. At the beginning of the Zuid-Holland longitudinal study the sample consisted of 1,106 boys and 1,060 girls. This sample was approached every two years until 1991 (Time 1-5), once in 1997 (Time 6), and again in 2006 (Time 7; for previous publications on these data waves see: Bongers et al. 2004; Hofstra et al. 2001; van Meurs et al. 2009). The present study is based on data from Time 1, Time 5, and Time 6. Given that the theoretical model suggested by Loeber et al. (2000) which we aimed to test in this study is age specific, we selected from all the participants of the Zuid-Holland longitudinal study, a subsample of participants who were aged 6-8 years (i.e., children in early childhood; 507 children/243 males) and had parent reports at Time 1 . These children were adolescents aged 14 to 16 at Time 5 (406 adolescents/187 males), and they were young adults aged 20 to 22 at Time 6 (421 adults/171 males). The ethnic composition of the sample was 97\% Dutch (remaining 3\% came from Surinam, the Dutch Antilles, and Morocco). We obtained parent ratings of children's behavioral and emotional problems at Time 1, and self-ratings of behavioral and emotional problems at Time 5 and Time 6 . We obtained written informed consent by all participants after the procedures were fully explained and the study was approved by the local ethical committee. Questionnaires were administrated by trained interviewers at each assessment.

Eighty percent of the participants had data in adolescence (i.e., Time 5) and $84 \%$ of the participants had data in young adulthood (i.e., Time 6). To investigate selective attrition we conducted $t$-tests comparing participants who remained in the study at Time 6 with participants who had dropped out of the study at Time 6 , on all study variables. There were no significant differences in any of the study variables between participants who remained or had dropped out of the study at Time 6
$(-1.44 \leq t \mathrm{~s} \leq 1.38, n s)$, but more males than females had dropped out of the study $\left(\chi^{2}(1)=13.32, p<0.01\right)$.

Measures

Behavioral and emotional problems in early childhood (Time 1) Parents rated their children's symptoms of ADHD and ODD over the last six months on the equivalent DSM-oriented scales of the Child Behavior Checklist (CBCL; Achenbach 1991; Achenbach and Rescorla 2001). The DSM-oriented scales were developed for the latest version of the CBCL (i.e., the 2001 version) and in this study an earlier version of the CBCL (i.e., the 1991 version) was used. The earlier version of the CBCL did not include all the items of the DSM-oriented scales so in the current study only 5 of the 13 items of the ADHD symptoms scale are included and only 4 out of 5 items of the ODD symptoms scale are included. As a measure of affective problems including anxiety, parents rated children's symptoms of anxiety/depression on the equivalent CBCL scale (Achenbach 1991). We chose the empirically based anxiety/depression scale over the DSM-oriented anxiety scale of the CBCL insofar as the latter scale has not shown satisfactory concurrent validity (Ferdinand 2008). Ratings were made on a three-point scale $(0=$ not true, $1=$ somewhat or sometimes true, 2 = very true or often true) and we used the summed score of items for all the scales (see scale items and internal consistency statistics for the scales measured as Cronbach's alpha in Table 1). Good reliability and validity measures for the Dutch version of the CBCL have been previously reported (Verhulst et al. 1996).

Behavioral and emotional problems in adolescence (Time 5) Adolescents rated their symptoms of depression, $\mathrm{CD}$, and somatic problems on, respectively, the affective problems-, the conduct problems-, and the somatic problems DSM-oriented scales of the Youth Self-Report (YSR; Achenbach 1991; Achenbach and Rescorla 2001). Due to the use of an earlier version of the YSR (i.e., the 1991 version), not all items of the DSM-oriented scale of CD symptoms are included (i.e., 10 out of 13) but all items of the affective problems and of the somatic problems scales are included in the current study. Ratings were made on a three-point scale as in the case of parent ratings (see above) and we used the summed score of items for all the scales. Scale items and internal consistency of the scales are presented in Table 1.

Adolescents also reported substance use on four questions (i.e., "Have you, in the last 6 months, been smoking", "Have you, in the last 6 months, been using non-medical drugs such as marijuana, hashish, amphetamines, cocaine, heroin, morphine, sleeping pills etc", "Have you, in the last 
Table 1 CBCL, YSR, and YASR Items Included in the Study

\begin{tabular}{|c|c|c|c|c|c|c|}
\hline \multicolumn{3}{|c|}{ Early childhood (CBCL) } & \multicolumn{3}{|c|}{ Adolescence (YSR) } & \multirow{2}{*}{$\begin{array}{l}\text { Young Adulthood (YASR) } \\
\text { APP }^{\mathrm{a}} \\
\alpha=0.75\end{array}$} \\
\hline $\begin{array}{l}\text { Anxiety/Depression } \\
\alpha=0.67\end{array}$ & $\begin{array}{l}\mathrm{ODD}^{\mathrm{a}} \\
\alpha=0.66\end{array}$ & $\begin{array}{l}\mathrm{ADHD}^{\mathrm{a}} \\
\alpha=0.74\end{array}$ & $\begin{array}{l}\text { Depression }^{\mathrm{a}} \\
\alpha=0.65\end{array}$ & $\begin{array}{l}\mathrm{CD}^{\mathrm{a}} \\
\alpha=0.66\end{array}$ & $\begin{array}{l}\text { Somatic problems }{ }^{\mathrm{a}} \\
\alpha=0.61\end{array}$ & \\
\hline Cries a lot & Argues a lot & Can't concentrate & Cries & Mean & Aches & Argues a lot \\
\hline Fears & Disobeys & Can't sit still & Harms self & Destroys others' & Headaches & Mean \\
\hline Fears at school & Stubborn & Impulsive & Worthless & No guilt & Nausea & Damages other's \\
\hline Fears doing bad & Hot temper & Talks too much & Guilty & Fights & Eye problems & Breaks rules \\
\hline Must be perfect & & Loud & Tired & Bad companions & Skin problems & Lacks guilt \\
\hline Feels unloved & & & Apathetic & Lies, cheats & Stomach & Bad relations w. fam. \\
\hline Feels worthless & & & Talks suicide & Attacks & Vomits & Fights \\
\hline Nervous & & & Threatens & Steals & & Bad companions \\
\hline Fearful & & & Sad & Swears & & Lies, cheats \\
\hline Feels too guilty & & & Underactive & Truant & & Attacks people \\
\hline Self-conscious & & & & & & Irresponsible behavior \\
\hline Talks of suicide & & & & & & Steals \\
\hline \multirow[t]{4}{*}{ Worries } & & & & & & Trouble with law \\
\hline & & & & & & Hot temper \\
\hline & & & & & & Threatens \\
\hline & & & & & & Fails to pay debts \\
\hline
\end{tabular}

$O D D$ oppositional defiant disorder symptoms; $A D H D$ attention deficit hyperactivity disorder symptoms; $C D$ conduct disorder symptoms; $A P P$ antisocial personality problems

${ }^{\text {a }}$ DSM-oriented scales

6 months, been drinking alcohol during weekdays, that is, from Monday to Thursday", "Have you, in the last 6 months, been drinking alcohol during the weekend, that is, from Friday to Sunday", $\alpha=0.61$ ). The response format was "Yes" (coded as 2) /"No" (coded as 1). A total of 11 adolescents used non-medical drugs, 87 adolescents smoked, 54 adolescents drank alcohol during weekdays, and finally, 184 adolescents drank alcohol during the weekends. Although smoking, alcohol and illicit drug use might as behaviors have very different individual effects, they can be combined into a single category insofar as previous studies suggest that the use of these three substances is correlated or comorbid (e.g., Farrell et al. 1992; Lynskaey et al. 1998) and also, because they comprise a general type of deviant behavior often associated with externalizing behavior problems (e.g., Timmermans et al. 2008). To accommodate for missing values (37 adolescents had missing values on one or more of the items) we chose to use the mean score of the four items over a summed score.

Antisocial personality problems in young adulthood (APP; Time 6) Young adults rated their antisocial personality problems on items of the Young Adult Self Report (YASR; Achenbach 1997) that correspond to 16 out of 20 items of the Adult Self Report (ASR; Achenbach and Rescorla
2001) scale of APP. Ratings were made on a three-point scale as in the case of parent ratings (see above) and we used the summed score of items for all the scales. Items and internal consistency of the scale are presented in Table 1.

Socioeconomic status (SES) Data on SES were obtained on the first assessment (Time 1) according to a six-step scaleascending numbers indicating higher SES-of parental education (van Westerlaak et al. 1975). SES was used only as a control variable (see Results). SES was significantly and negatively related only to ODD symptoms $(r=-0.15$, $p<0.01)$ and to ADHD symptoms $(r=-0.13, p<0.01)$ in early childhood.

\section{Statistical Analyses}

We first computed Pearson's correlation coefficients to assess the relations between all study variables and examined gender differences in all variables with twotailed $t$-tests. We tested the theoretical model depicted in Fig. 1 by conducting path analyses, that is, by fitting a series of structural equation models with manifest variables. Model parameters were estimated with the M-plus software program (Muthén and Muthén 1998-2007). Because the data departed from multivariate normality (see Table 2) we 
used maximum likelihood parameter estimates with standard errors that are robust to non-normality (i.e., MLR). Maximum likelihood estimation procedure is particularly appropriate for longitudinal studies which often contain missing data (Schafer and Graham 2002). The goodness-offit of the models was evaluated by using two indicators: the Root Mean Square Error of Approximation (RMSEA) where values below 0.06 indicate a good fit and values below 0.08 indicate a moderate fit (Brown and Cudeck 1993), and the Comparative Fit Index (CFI) where values larger than 0.90 or close to 0.95 indicate a good fit (Hu and Bentler 1999). Chi-square difference analyses guided decisions concerning selection of the best fitting model (i.e., the Satorra-Bentler scaled chi-square difference test which is appropriate for models estimated with MLR; Satorra and Bentler 2001). To investigate whether the final model would fit differently for boys and girls, we used a multi-group comparison approach (Muthén and Muthén 1998-2007).

\section{Results}

Descriptive statistics for all study variables are depicted in Table 2 and the correlation matrix for all study variables is depicted in Table 3. As shown in Table 3, APP were predicted by ODD symptoms in early childhood and CD symptoms and substance use in adolescence, but, they were not predicted by ADHD symptoms or by any of the measures of internalizing problems. Furthermore, CD symptoms in adolescence were predicted by both ODD and ADHD symptoms in early childhood. Concurrent associations indicated a significant overlap between symptoms of ODD, ADHD, and anxiety/depression symptoms in early childhood and between symptoms of depression, somatic problems, and substance use in adolescence.

In terms of gender differences, males had higher levels of ODD and ADHD symptoms in early childhood and they reported higher levels of substance use in adolescence and of APP in young adulthood $(2.63 \leq t \mathrm{~s} \leq 3.50, p<0.01$; effect sizes for these comparisons measured as Cohen's $d$ : $0.26 \leq d \mathrm{~s} \leq 0.39$ ). Adolescent females reported higher levels of depression symptoms; $t(385)=-6.07, p<0.01$, $d=0.62$; and of somatic problems; $t(393)=-5.44, p<0.01$, $d=0.55$.

Table 4 depicts model fit indices and model comparisons for the test of the theoretical model by Loeber et al. (2000) and the alternative model, adjusted for SES at Time 1. In Model 1, single-headed arrows depicted in Fig. 1 (dotted arrows also) designated regression coefficients and bidirectional arrows signified covariances. We treated the non-directional line between symptoms of anxiety and depression also as a regression coefficient. As shown in Table 4, this model did not fit the data. Therefore, three modifications, each consistent with theory, were made to improve model fit. First, consistent with previous empirical work suggesting a high degree of overlap between somatic problems and depression (for a review see: Compas et al. 1993), we included in the model a covariance between the residuals of these two constructs (Model 2). Next, consistent with previous reports of a positive association between ADHD symptoms and symptoms of anxiety and depression (e.g., Angold et al. 1999; Jensen et al. 2001), we included a covariance between the residuals of ADHD symptoms and symptoms of anxiety/depression (Model 3). Finally, consistent with previous reports of a positive association between childhood ODD symptoms and anxiety (for a review see Angold et al. 1999), we included a covariance between the residuals of ODD symptoms and symptoms of anxiety/ depression (Model 4). We made no further modifications to this model as we obtained satisfactory model fit statistics.

We then proceeded to examine whether co-occurring affective problems and substance use in adolescence added to the prediction of APP in young adulthood from conduct problems in adolescence. Therefore we tested an alternative model (i.e., Model 5) which was as Model 1 but included also paths to APP in young adulthood from depression symptoms, somatic problems, and substance use in adolescence. As seen in Table 4, initially, this model did not fit the data. After applying model modifications in the same manner as above, the model (i.e., Model 8) fitted the data well. In this model, neither the path to APP from depression symptoms $(\beta=-0.05, n s)$, nor the path to APP from somatic problems $(\beta=0.01, n s)$, were significant. The path to APP from CD symptoms was significant $(\beta=0.31, p<$ 0.01 ) but the path to APP from substance use just missed significance $(\beta=0.15, p=0.06)$. Finally, considering Model 8 and Model 4 as nested models, we conducted a chi-square difference test to examine which model fitted the data best. The results revealed that Model 8 did not fit the data better than Model 4, $\Delta \chi^{2}(4)=10.72, n s$. Hence, given that the paths to APP from internalizing problems and substance use were not significant, and also because it was the more parsimonious model, we chose Model 4 as the final path model. This model explained a total of $12 \%$ of the variance in APP.

Figure 2 displays the standardized estimates for the effects within the final path model (i.e., Model 4). Results revealed that ODD symptoms in early childhood were significant predictors of both depression and CD symptoms in adolescence. Symptoms of CD in adolescence were significant predictors of APP in early adulthood. Furthermore, there was a significant path to ODD symptoms from ADHD symptoms in early childhood indicating that the 
Table 2 Descriptive Statistics of All Study Variables

\begin{tabular}{|c|c|c|c|c|c|c|c|c|}
\hline & $\mathrm{M}(\mathrm{SD})$ & Min/Max & $\%$ Min & $\% \operatorname{Max}$ & Skewness & Kurtosis & Shapiro- & k statistic \\
\hline Family SES & $3.49(1.55)$ & $1 / 6$ & 5.43 & 15.28 & 0.28 & -1.21 & 0.88 & $p<0.01$ \\
\hline \multicolumn{9}{|l|}{ Early Childhood } \\
\hline Anxiety/Depression symptoms & $2.46(2.50)$ & $0 / 14$ & 25.15 & 0.41 & 1.46 & 2.63 & 0.84 & $p<0.01$ \\
\hline ODD symptoms & $1.59(1.65)$ & $0 / 8$ & 32.92 & 0.41 & 1.12 & 0.96 & 0.85 & $p<0.01$ \\
\hline ADHD symptoms & $2.85(2.54)$ & $0 / 10$ & 22.29 & 1.84 & 0.78 & -0.11 & 0.90 & $p<0.01$ \\
\hline \multicolumn{9}{|l|}{ Adolescence } \\
\hline Depression symptoms & $2.85(1.84)$ & $0 / 10$ & 3.08 & 0.77 & 1.35 & 2.29 & 0.87 & $p<0.01$ \\
\hline CD symptoms & $2.20(2.02)$ & $0 / 13$ & 18.21 & 0.26 & 1.35 & 2.55 & 0.87 & $p<0.01$ \\
\hline Somatic problems & $1.96(2.20)$ & $0 / 13$ & 34.36 & 0.26 & 1.40 & 2.23 & 0.83 & $p<0.01$ \\
\hline Substance use & $1.21(0.26)$ & $1 / 2$ & 50.39 & 1.80 & 1.06 & 0.23 & 0.78 & $p<0.01$ \\
\hline \multicolumn{9}{|l|}{ Young adulthood } \\
\hline Antisocial personality problems & $3.38(2.76)$ & $0 / 14$ & 10.03 & 0.50 & 1.30 & 1.62 & 0.87 & $p<0.01$ \\
\hline
\end{tabular}

higher levels of ADHD symptoms children displayed the higher levels of ODD symptoms they had. Finally, despite the positive correlations between the constructs (see Table 3), the path to depression symptoms from anxiety/ depression symptoms was not significant and neither was the path to CD symptoms from ADHD symptoms significant. Because the theoretical model proposed by Loeber et al. (2000) suggests that ADHD symptoms serve to exacerbate the relation between ODD and CD symptoms, we tested whether the association between ODD and CD symptoms was moderated by symptoms of ADHD. To test this latter association we included in the model an interaction effect between ADHD and ODD symptoms predicting $\mathrm{CD}$ symptoms in adolescence. This path did not reach significance $(\beta=-0.09, n s)$.

To examine whether the final model (i.e., Model 4) would fit the data differently for males and females, we compared the fit of two competing models, one in which all paths and covariances of the final model were constrained to be equal across gender (the constrained model) and another in which all paths and covariances of the final model were allowed to differ across gender (the unconstrained model). A chi-square difference test $\left(\Delta \chi^{2}[19]=\right.$ $-98.92, p<0.01)$ revealed that the unconstrained model $\left(\chi^{2}\right.$ $[40]=59.20, \mathrm{CFI}=0.96$, RMSEA $=0.04)$ fitted the data better than the constrained model $\left(\chi^{2}[59]=166.38\right.$; CFI $=$ 0.74 , RMSEA $=0.08$ ). To examine which associations between variables differed for males and females, we conducted chi-square difference tests comparing the fit of the fully constrained model with the fit of a partly constrained model in which one association at a time (i.e., path or covariance) was freed whereas all other associations were constrained to be equal. The results revealed two significant gender differences: First, the path to ODD symptoms from ADHD symptoms differed by gender $\left(\Delta \chi^{2}[3]=61.12, p<0.01\right)$ and was slightly stronger for females $(\beta=0.50, p<0.01)$ than for males $(\beta=0.47, p<$ $0.01)$. Second, the covariance between somatic problems

Table 3 Correlation Matrix for All Study Variables

\begin{tabular}{|c|c|c|c|c|c|c|c|c|}
\hline & 1. & 2. & 3. & 4. & 5. & 6. & 7. & 8. \\
\hline \multicolumn{9}{|l|}{ Early Childhood } \\
\hline 1. Anxiety/Depression symptoms & 1.00 & $0.44 * *$ & $0.38 * *$ & $0.15^{* *}$ & 0.05 & $0.10^{*}$ & 0.08 & 0.08 \\
\hline 2. ODD symptoms & & 1.00 & $0.51 * *$ & $0.15^{* *}$ & $0.26^{* *}$ & 0.06 & 0.07 & $0.19^{* *}$ \\
\hline 3. ADHD symptoms & & & 1.00 & 0.05 & $0.18^{* *}$ & 0.00 & 0.07 & 0.08 \\
\hline \multicolumn{9}{|l|}{ Adolescence } \\
\hline 4. Depression symptoms & & & & 1.00 & $0.34 * *$ & $0.56^{* *}$ & $0.29 * *$ & 0.09 \\
\hline 5. CD symptoms & & & & & 1.00 & $0.25 * *$ & $0.33^{* *}$ & $0.34 * *$ \\
\hline 6. Somatic problems & & & & & & 1.00 & $0.12 *$ & 0.09 \\
\hline 7. Substance use & & & & & & & 1.00 & $0.24 * *$ \\
\hline \multicolumn{9}{|l|}{ Young adulthood } \\
\hline 8. Antisocial personality problems & & & & & & & & 1.00 \\
\hline
\end{tabular}

$* p<0.05 ; * * p<0.01$ 
Table 4 Model Fit Indices and Model Comparisons

\begin{tabular}{|c|c|c|c|c|c|c|c|}
\hline & & $x^{2}$ & df & CFI & RMSEA & & $\Delta \chi^{2}(\mathrm{df})$ \\
\hline M1 & $\begin{array}{l}\text { Single-headed arrows treated as paths, double-headed arrows } \\
\text { and lines without arrow-heads treated as covariances }\end{array}$ & $244.15^{* *}$ & 23 & 0.57 & 0.13 & & \\
\hline M2 & As M1, plus a correlation between Som. pr. and Dep. symptoms & $120.41 * *$ & 22 & 0.81 & 0.09 & $(1$ vs 2$)$ & 92.55 (1) $p<0.01$ \\
\hline M3 & As M2, plus a correlation between ADHD and Anx/Dep symptoms & $48.42 * *$ & 21 & 0.94 & 0.05 & $(2$ vs 3$)$ & 62.66 (1) $p<0.01$ \\
\hline M4 & As M3 plus a correlation between ODD and Anx/Dep symptoms & 29.25 & 20 & 0.98 & 0.03 & (3 vs 4$)$ & $14.56(1) p<0.01$ \\
\hline M5 & $\begin{array}{l}\text { As Model } 1 \text { but including also paths to APP from Dep. } \\
\text { symptoms, Substance use, and Som. pr. }\end{array}$ & $239.05^{* *}$ & 19 & 0.56 & 0.14 & & \\
\hline M6 & As M5, plus a correlation between Som. pr. and Dep. symptoms & $109.80^{* *}$ & 18 & 0.81 & 0.09 & (5 vs 6$)$ & $101.31(1) p<0.01$ \\
\hline M7 & As M6, plus a correlation between ADHD and Anx/Dep symptoms & $37.65 * *$ & 17 & 0.96 & 0.04 & (6 vs 7$)$ & 61.87 (1) $p<0.01$ \\
\hline M8 & As M7 plus a correlation between ODD and Anx/Dep symptoms & 18.29 & 16 & 0.99 & 0.02 & (7 vs 8$)$ & 14.56 (1) $p<0.01$ \\
\hline
\end{tabular}

Som. $p r$ somatic problems; Anx/Dep anxiety/depression symptoms; APP antisocial personality problems; Dep. depression symptoms

${ }^{a}$ Except for the association between Anx/Dep and CD symptoms

$* * p<0.01$

and depression symptoms differed by gender $\left(\Delta \chi^{2}[1]=\right.$ 9.05, $p<0.01)$, and was stronger for females $(\rho=0.55, p<$ $0.01)$ than for males $(\rho=0.34, p<0.01)$. Hence, apart from the two above associations which were somewhat stronger for females than for males, the paths to APP in young adulthood from disruptive behavior problems in early childhood and internalizing problems as well as substance use in adolescence were the same for boys and girls.

\section{Discussion}

In this study we tested a theoretical model (Loeber et al. 2000) predicting APP in young adulthood from disruptive behavior problems and internalizing problems in early childhood and adolescence. We also compared this model to an alternative model including direct paths to APP from internalizing problems and substance use in adolescence. The findings supported the proposed theoretical model by Loeber et al. (2000) by confirming the continuity of antisocial behavior starting with milder forms of disruptive behaviors in early childhood (i.e., symptoms of ODD and ADHD), followed by conduct problems in adolescence, and finally cumulating into adult APP. The findings on the alternative model we tested suggested that in spite of being positively associated with conduct problems in adolescence, internalizing problems and substance use did not add to the prediction of adult APP over and above the effects of

Early Childhood (age 6-8)

Adolescence (age 14-16)

Young Adulthood (age 20-22)

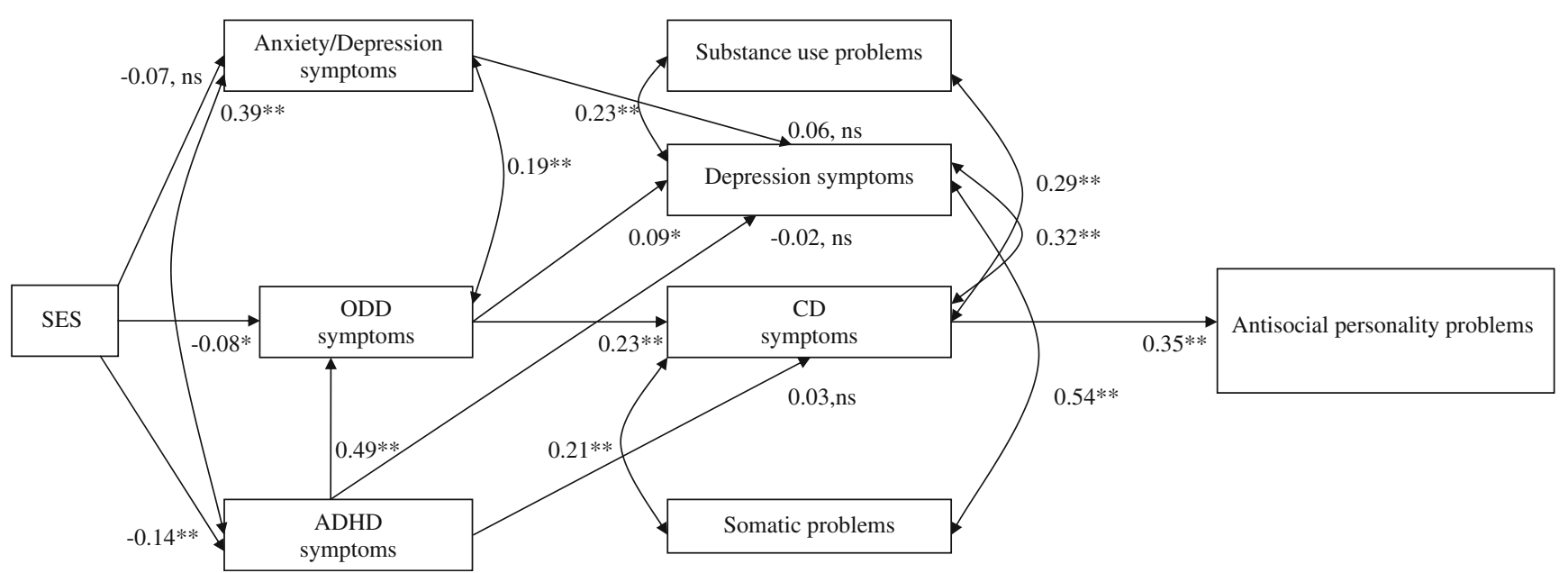

Fig. 2 Illustration of final path analysis model showing the developmental sequences between disruptive behaviors- and cooccurring problems in childhood and adolescence and antisocial personality problems in young adulthood. Single-headed arrows are path coefficients and curved, bidirectional arrows represent covariances. All estimates are standardized. Constructs in boxes are manifest, measured, variables. ${ }^{*} p<0.05, * * p<0.01, n s$ non-significant 
adolescent conduct problems. The paths to APP in young adulthood did not differ by gender.

This study extends prior work on the development of antisocial behavior in several ways. The power of the findings comes from three features that have not been presented in many other studies. First, the combination of a lengthy follow-up period and systematic, theoretical investigation puts the present study in a good position to provide a life-course perspective on the development of antisocial problems. The longitudinal design of this study highlights also the usefulness of assessing different forms of antisocial behavior and affective problems at key developmental periods to identify underlying liabilities leading to APP in young adulthood. Second, while this study was not designed to test hypotheses regarding reasons of comorbidity, the results provide support for the notion that common risk factors underlie the development of disruptive behavior problems insofar as they showed a significant overlap in the early stages of antisocial behavior. Notably, in the present study we assessed comorbidity using a dimensional approach the advantage of which is that it does not miss potentially informative covariation in symptoms as categorical approaches do. Third, we examined gender differences which allowed us to test the existence of a female-specific pathway to APP.

The present findings have several important implications for clinical research. First, the findings confirm previous suggestions that prevention of the initial onset of conduct problems is key to preventing antisocial behavior (Tremblay and Japel 2003). Second, although we found no direct link between adolescent internalizing problems and APP in young adulthood, because internalizing problems were positively related to conduct problems in adolescence, future intervention studies need to examine whether targeting internalizing problems is likely to reduce the association between conduct problems and APP. However, it should be noted that results of longitudinal path analyses should not be interpreted as causal effects although they do provide an indication as to how developmental phenomena are related through time. The above information may help clinicians to design improved preventive and early intervention programs. From a public health perspective, the ability to predict the course of antisocial behavior over the long term could help to focus limited societal resources on those with persistent antisocial behavior problems with complicated outcomes.

Not all the associations predicted by the theoretical model by Loeber et al. (2000) were established in this study. First, despite a significant, although weak, positive association between anxiety/depression symptoms in early childhood and depression symptoms in adolescence, the equivalent path was not significant. A number of explanations for this observation can be put forward. It may well be the case that the psychometric properties of the CBCL anxiety/depression subscale and the YSR depression subscale in our sample were insufficient to capture children's internalizing problems in early childhood and adolescence. This is partly supported by the rather modest reliability coefficients obtained for both scales. Cross-informant discrepancies may also explain the above finding. Previous studies have reported low cross-sectional correlations between parent- and self-reports of internalizing problems (e.g., Ferdinand et al. 2004). Nevertheless, anxiety symptoms did appear to positively influence the development of milder forms of antisocial behavior in early childhood insofar as anxiety/depression symptoms in early childhood were positively related to both concurrent ADHD and ODD symptoms. These latter findings are in line with previous reports showing that the co-occurrence of anxiety with disruptive behavior problems appears to be highest during middle childhood (i.e., around the ages of 7 to 9; Loeber and Keenan 1994; Russo and Beidel 1994).

Second, we did not find a direct association between ADHD symptoms in early childhood and conduct problems in adolescence. We also did not obtain a significant interaction effect between ODD and ADHD symptoms predicting CD symptoms, although the model proposes that ADHD symptoms in the presence of ODD symptoms serve to hasten the onset of $\mathrm{CD}$. Despite these findings, the present study leaves open the possibility that hyperactiveimpulsive and inattentive behaviors may worsen the outcome of children displaying antisocial behaviors. Symptoms of ADHD may for instance reflect an innate impediment to behavioral control which could perhaps exacerbate already present antisocial tendencies in children.

Inconsistent with our alternative model and with previous studies (Fombonne et al. 2001; Sourander et al. 2007), neither depression nor somatic problems in adolescence appeared to add to the prediction of antisocial problems in young adulthood. A reason for this discrepant finding could be that whereas this study examined associations between continuous variables in the general population, previous studies utilized a categorical approach and examined associations in clinical samples (Fombonne et al. 2001; Sourander et al. 2007). Hence, co-occurring conduct and internalizing problems appear to carry an elevated risk for the development of APP only among adolescents displaying highly elevated levels of these problems. Furthermore, the results of the alternative model did not confirm previous findings suggesting that substance use is a significant predictor of APP (e.g., Washburn et al. 2007) although the bivariate relations revealed a positive correlation between substance use and APP. It should however be noted that our measure of substance use mainly reflected alcohol use insofar as only few adolescents used illicit drugs or smoked and, given that we examined a normal population sample, approximately $50 \%$ of the sample did 
not report any substance use at all. Consequently, because lack of power may explain these latter findings they should be viewed as preliminary until replicated in future studies.

The only gender differences we obtained in this study indicated that the relation between ADHD and ODD symptoms in early childhood and the relation between somatic problems and depression among adolescents were slightly stronger for females than for males. Hence, the cumulative development of antisocial behavior from early childhood to young adulthood did not differ by gender and our results did not confirm the existence of a femalespecific pathway for the development of APP (Silverthorn and Frick 1999). Nevertheless, gender differences in the behavioral manifestation of antisocial behaviors have been found, with females being more likely than males to show less overt physical forms of aggression and more indirect, relational, and nonphysical forms of aggression (e.g., Crick and Grotpeter 1995; Lösel and Bender 2003). Recent findings also suggest that relational aggression is associated with impulsive antisociality in females but not in males (Ostrov and Houston 2008). Consequently, future studies on the issue need to include measures tapping indirect forms of aggression to establish whether there indeed exist gender differences in the developmental paths leading to APD.

It is important to consider the present findings in the context of the limitations of this study. It is well established in the literature that conduct problems are multi-causally determined and reflect the aggregate effects of social, family (including genetic), individual, peer and other factors that act in combination to influence and determine levels of behavioral adjustment in childhood and adolescence. Insofar as the aim of this study was to examine a proposed theoretical model, we did not include other possible predictors that may be important markers of APP such as callous-unemotional traits (Frick and White 2008; Lynam 1996) and deviant peer affiliations (Lösel and Bender 2003). Some of our findings are also limited by the testing of a specific theoretical model. For instance, the finding that the effects of ODD symptoms on $\mathrm{CD}$ symptoms were not moderated by ADHD symptoms is limited by the fact that ODD and ADHD symptoms were measured concurrently. Furthermore, our sample did not allow for the examination of ethnic differences although previous studies have either reported no ethnic differences in the development of APD (Washburn et al. 2007), or have concluded that low SES accounts for such differences (Lahey et al. 2005). Finally, the internal consistency of the CBCL, YSR, and YASR scales was relatively low, although it was not lower than that reported in the instruments' manuals (Achenbach 1991, 1997; Achenbach and Rescorla 2001).

Despite the above limitations we pose that the results of the present study have considerable significance for the early recognition and treatment of antisocial behavior problems. The findings suggest that to prevent the development of antisocial personality problems in adulthood, particular attention should be given to preventing the emergence of, first, ODD symptoms, and second, CD symptoms. It should nevertheless be noted that the specificity of conduct problems as a predictor for APD is poor given that they have been found to precede nearly every mental disorder in adulthood in population samples (Kim-Cohen et al. 2003). Furthermore, it may not be conduct problems per se that lead to antisocial problems in adulthood but underlying psychological processes such as negative emotionality or an interaction of neurocognitive processes (Lösel and Bender 2003). However, the association between CD symptoms in adolescence and APP in young adulthood stresses the importance of assessing the developmental history of adult patients to inform treatment strategy. Prior research suggests that life-course persistent antisocial behavior has more serious adult consequences than antisocial behavior limited to a specific developmental period (e.g., Moffitt 1993; Loeber and Farrington 2000). Finally, knowing when disorders are likely to first appear can help early intervention planning. Additional studies that address protective factors (e.g., family and social support systems and the child's cognitive and social skills) are warranted as well as studies examining gender differences in the developmental pathways leading to adult APP which include measures tapping female types of aggression.

Acknowledgments Support for the first author was provided by The Swedish Council for Working Life and Social Research.

Open Access This article is distributed under the terms of the Creative Commons Attribution Noncommercial License which permits any noncommercial use, distribution, and reproduction in any medium, provided the original author(s) and source are credited.

\section{References}

Abramowitz, C. S., Kosson, D. S., \& Seidenberg, M. (2004). The relationship between childhood attention deficit hyperactivity disorder and conduct problems and adult psychopathy in male inmates. Personality and Individual Differences, 36, 1031-1047.

Achenbach, T. M. (1991). Manual for the child behavior checklist/418 and 1991 profile. Burlington: University of Vermont, Department of Psychiatry.

Achenbach, T. M. (1997). Manual for the young adult self-report and young adult behavior checklist. Burlington: University of Vermont, Department of Psychiatry.

Achenbach, T. M., \& Rescorla, L. A. (2001). Manual for the ASEBA school-age forms \& profiles. Burlington: University of Vermont, Research Center for Children, Youth, \& Families.

American Psychiatric Association. (1994). Diagnostic and statistical manual of mental disorders (4th ed.). Washington: American Psychiatric Association.

Angold, A., Costello, E., \& Erkanli, A. (1999). Comorbidity. Journal of Child Psychology and Psychiatry, 40, 57-97. 
Armstrong, T., \& Costello, E. J. (2002). Community studies on adolescent substance use, abuse, or dependence and psychiatric comorbidity. Journal of Consulting and Clinical Psychology, 70, $1224-1239$.

Biederman, J., Faraone, S., Mick, E., \& Lelon, E. (1995). Psychiatric comorbidity among referred juveniles with major depression: fact or artifact? Journal of the American Academy of Child and Adolescent Psychiatry, 34, 579-590.

Black, D. W., Baumgard, C. H., Bell, S. E., \& Kao, C. (1996). Death rates in 71 men with antisocial personality disorder. Psychosomatics, 37, 131-136.

Bongers, I. L., Koot, H. M., van der Ende, J., \& Verhulst, F. C. (2004). Developmental trajectories of externalizing behaviors in childhood and adolescence. Child Development, 75, 1523-1537.

Brown, M., \& Cudeck, R. (1993). Alternative ways of assessing model fit. In K. Bollen \& J. Long (Eds.), Testing structural equation models (pp. 136-162). London: Sage.

Burke, J. D., Loeber, R., \& Birmaher, B. (2002). Oppositional defiant disorder and conduct disorder: a review of the past 10 years, Part II. Journal of the American Academy of Child and Adolescent Psychiatry, 41, 1275-1293.

Burke, J. D., Loeber, R., Lahey, B. B., \& Rathouz, P. J. (2005). Developmental transitions among affective and behavioral disorders in adolescent boys. Journal of Child Psychology and Psychiatry, 46, 1200-1210.

Compas, B. E., Ey, S., \& Grant, K. E. (1993). Taxonomy, assessment, and diagnosis of depression during adolescence. Psychological Bulletin, 114, 323-344.

Copeland, W. E., Miller-Johnson, S., Keeler, G., \& Angold, A. (2007). Childhood psychiatric disorders and young adult crime: a prospective, population-based study. American Journal of Psychiatry, 164, 1668-1675.

Costello, E. J., Mustillo, S., Erkanli, A., Keeler, G., \& Angold, A. (2003). Prevalence and development of psychiatric disorders in childhood and adolescence. Archives of General Psychiatry, 60, 837-844.

Crick, N. R., \& Grotpeter, J. K. (1995). Relational aggression, gender, and social-psychological adjustment. Child Development, 66, 710-722.

de Graaf, R., Bijl, R. V., Spijker, J., Beekman, A. T. F., \& Vollebergh, W. A. M. (2003). Temporal sequencing of lifetime mood disorders in relation to comorbid anxiety and substance use disorders: findings from the Netherlands mental health survey and incidence study. Social Psychiatry and Psychiatric Epidemiology, 38, 1-11.

Dolan, B., \& Coid, J. (1993). Psychopathic and antisocial personality disorders. Treatment and research issues. London: Gaskell.

D’Onofrio, B. M., Goodnight, J. A., Van Hulle, C. A., Rodgers, J. L., Rathouz, P. J., Waldman, I. D., et al. (2009). A quasiexperimental analysis of the association between family income and offspring conduct problems. Journal of Abnormal Child Psychology, 37, 415-429.

Farrell, A. D., Danish, S. J., \& Horward, C. W. (1992). Relationship between drug use and other problem behaviors in urban adolescents. Journal of Consulting and Clinical Psychology, 60, 705-712.

Ferdinand, R. F. (2008). Validity of the CBCL/YSR DSM-IV scales anxiety problems and affective problems. Journal of Anxiety Disorders, 22, 126-134.

Ferdinand, R. F., van der Ende, J., \& Verhulst, F. C. (2004). Parentadolescent disagreement regarding psychopathology in adolescents from the general population as a risk factor for adverse outcome. Journal of Abnormal Psychology, 113, 198-206.

Fergusson, D. M., \& Horwood, L. J. (1998). Early conduct problems and later life opportunities. Journal of Child Psychology and Psychiatry, 39, 1097-1108.

Fergusson, D. M., Horwood, L. J., \& Ridder, E. M. (2005). Show me the child at seven: the consequences of conduct problems in childhood for psychosocial functioning in adulthood. Journal of Child Psychology and Psychiatry, 46, 837-849.

Fombonne, E., Wostear, G., Cooper, V., Harrington, R., \& Rutter, M. (2001). The Maudsley long-term follow-up of child and adolescent depression. 1. Psychiatric outcomes in adulthood. British Journal of Psychiatry, 179, 210-217.

Frick, P. J., \& White, S. F. (2008). Research review: the importance of callous-unemotional traits for developmental models of aggressive and antisocial behavior. Journal of Child Psychology and Psychiatry, 49, 359-375.

Hill, J. (2003). Early identification of individuals at risk for antisocial personality disorder. British Journal of Psychiatry, 182(Supplement 144), 11-14.

Hinshaw, S., Lahey, B. B., \& Hart, E. L. (1993). Issues of taxonomy and comorbidity in the development of conduct disorder. Development and Psychopathology, 5, 31-49.

Hodgins, S., \& Cote, G. (1993). The criminality of mentally disordered offenders. Criminal Justice and Behaviour, 20, 115129.

Hofstra, M. B., van der Ende, J., \& Verhulst, F. C. (2001). Adolescents'self-reported problems as predictros of psychopathology in adulthood: a 10-year follow-up study. British Journal of Psychiatry, 179, 203-209.

Hu, L. T., \& Bentler, P. M. (1999). Cutoff criteria for fit indexes in covariance structure analysis: conventional criteria versus new alternatives. Structural Equation Modeling, 6, 1-55.

Jensen, P. S., Hinshaw, S. P., Kraemer, H. C., Lenora, N., Newcorn, J. H., Abikoff, H. B., et al. (2001). ADHD comorbidity findings from the MTA study: comparing comorbid subgroups. Journal of the American Academy of Child and Adolescent Psychiatry, 40, $147-158$.

Kasen, S., Cohen, P., Skodol, A. E., Johnson, J. G., Smailes, E., \& Brook, J. S. (2001). Childhood depression and adult personality disorder: alternative pathways of continuity. Archives of General Psychiatry, 58, 231-236.

Kerr, M., Tremblay, R. E., Pagani, L., \& Vitaro, F. (1997). Boys' behavioral inhibition and risk for later delinquency. Archives of General Psychiatry, 54, 809-816.

Kim-Cohen, J., Caspi, A., Moffitt, T. E., Harrington, H., Milne, B. J., \& Poulton, R. (2003). Prior juvenile diagnoses in adults with mental disorder: developmental follow-back of a prospectivelongitudinal cohort. Archives of General Psychiatry, 60, 709717.

Kovacs, M., Paulauskas, S., Gatsonis, C., \& Richards, C. (1988). Depressive disorders in childhood: III. A longitudinal study of comorbidity with and risk for conduct disorders. Journal of Affective Disorders, 15, 205-217.

Kratzer, L., \& Hodgins, S. (1997). Adult outcomes of child conduct problems: a cohort study. Journal of Abnormal Child Psychology, $25,65-81$.

Lahey, B. B., McBurnett, K., \& Loeber, R. (2000). Are attentiondeficit/hyperactivity disorder and oppositional defiant disorder developmental precursors to conduct disorder? In A. Samenoff, M. Lewis \& S. M. Miller (Eds.), Handbook of developmental psychopathology (2nd ed., pp. 431-446). New York: Plenum.

Lahey, B. B., Loeber, R., Burke, J. D., \& Applegate, B. (2005). Predicting future antisocial personality disorder in males from a clinical assessment in childhood. Journal of Consulting and Clinical Psychology, 73, 389-399.

Lilienfeld, S. O. (1992). The association between antisocial personality and somatization disorders: a review and integration of theoretical models. Clinical Psychology Review, 12, $641-662$.

Loeber, R., \& Farrington, D. P. (2000). Young children who commit crime: epidemiology, developmental origins, risk factors, early 
interventions, and policy implications. Development and Psychopathology, 12, 737-762.

Loeber, R., \& Keenan, K. (1994). Interaction between conduct disorder and its comorbid effects of age and gender. Clinical Psychology Review, 14, 497-523.

Loeber, R., Burke, J. D., Lahey, B. B., Winters, A., \& Zera, M. (2000). Oppositional defiant disorder and conduct disorder: a review of the past 10 years, part I. Journal of the American Academy of Child and Adolescent Psychiatry, 39, $1468-1484$

Loeber, R., Burke, J. D., \& Lahey, B. B. (2002). What are adolescent antecedents to antisocial personality disorder? Criminal Behaviour and Mental Health, 12, 24-36.

Loeber, R., Green, S. M., \& Lahey, B. B. (2003). Risk factors for adult antisocial personality. In D. P. Farrington \& J. W. Coid (Eds.), Early prevention of adult antisocial behaviour (pp. 79-108). Cambridge: Cambridge University Press.

Lösel, F., \& Bender, D. (2003). Protective factors and resilience. In D. P. Farrington \& J. W. Coid (Eds.), Early prevention of adult antisocial behaviour (pp. 130-204). Cambridge: Cambridge University Press.

Lynam, D. R. (1996). Early identification of chronic offenders: who is the fledging psychopath? Psychological Bulletin, 120, 209-234.

Lynskaey, M. T., Fergusson, D. M., \& Horwood, L. J. (1998). The origins of the correlations between tobacco, alcohol, and cannabis use during adolescence. Journal of Child Psychology and Psychiatry, 39, 995-1005.

Mannuzza, S., Klein, R. G., Bessler, A., Malloy, P., \& LaPadula, M. (1993). Adult outcome of hyperactive boys: educational achievement, occupational rank, and psychiatric status. Archives of General Psychiatry, 50, 565-576.

Maughan, B., \& Rutter, M. (2001). Antisocial children grow up. In J. Hill \& B. Maughan (Eds.), Conduct disorders in childhood and adolescence (pp. 507-552). New York: Cambridge University Press.

Maughan, B., Rowe, R., Messer, J., Goodman, R., \& Meltzer, H. (2004). Conduct disorder and oppositional defiant disorder in a national sample: developmental epidemiology. Journal of Child Psychology and Psychiatry, 45, 609-621.

Moffitt, T. E. (1993). Adolescence-limited and life-course persistent antisocial behavior: a developmental taxonomy. Psychological Review, 100, 674-701.

Moffitt, T. E., Caspi, A., Rutter, M., \& Silva, P. (2001). Sex differences in antisocial behaviour. Cambridge: Cambridge University Press.

Monuteaux, M. C., Faraone, S. V., Gross, L. M., \& Biederman, J. (2007). Predictors, clinical characteristics, and outcome of conduct disorder in girls with attention-deficit/hyperactivity disorder: a longitudinal study. Psychological Medicine, 37, $1731-1741$.

Moran, P. (1999). Antisocial personality disorder: An epidemiological perspective. London: Gaskell.

Muthén, L. K., \& Muthén, B. O. (1998-2007). Mplus user's guide (5th ed.). Los Angeles: Muthén \& Muthén.

Nock, M., Kazdin, A., Hiripi, E., \& Kessler, R. (2006). Prevalence, subtypes, and correlates of DSM-IV conduct disorder in the national comorbidity survey replication. Psychological Medicine, 36, 699-710.

Ostrov, J. M., \& Houston, R. J. (2008). The utility of forms and functions of aggression in emerging adulthood: association with personality disorder symptomatology. Journal of Youth and Adolescence, 37, 1147-1158.
Rhee, S. H., \& Waldman, I. D. (2002). Genetic and environmental influences on antisocial behavior: a meta-analysis of twin and adoption studies. Psychological Bulletin, 128, 490-529.

Russo, M. F., \& Beidel, D. C. (1994). Comorbidity of childhood anxiety and externalizing disorders: prevalence, associated characteristics, and validation issues. Clinical Psychology Review, 14, 199-221.

Salekin, R. T., Neumann, C. S., Leistico, A.-M. R., DiCicco, T. M., \& Duros, R. L. (2004). Psychopathy and comorbidity in a young offender sample: taking a closer look at psychopathy's potential importance over disruptive behavior disorders. Journal of Abnormal Psychology, 113, 416-427.

Satorra, A., \& Bentler, P. M. (2001). A scaled difference chi-square test statistic for moment structure analysis. Psychometrika, 66, 507-514.

Schafer, J. L., \& Graham, J. W. (2002). Missing data: our view of the state of the art. Psychological Methods, 7, 147-177.

Silverthorn, P., \& Frick, P. J. (1999). Developmental pathways to antisocial behavior: the delayed-onset pathway in girls. Development and Psychopathology, 11, 101-126.

Sourander, A. M., Multimaki, P. M., Nikolakaros, G. M., Haavisto, A. M., Ristkari, T. M., Helenius, H. M., et al. (2005). Childhood predictors of psychiatric disorders among boys: a prospective community-based follow-up study from age 8 years to early adulthood. Journal of the American Academy of Child and Adolescent Psychiatry, 44, 756-767.

Sourander, A. M., Jensen, P., Davies, M., Niemelä, S., Elonheimo, H., Ristkari, T., et al. (2007). Who is at risk for adverse long-term outcomes? The Finnish from a boy to a man study. Journal of the American Academy of Child and Adolescent Psychiatry, 46, $1148-1161$.

Storm-Mathisen, A., \& Vaglum, P. (1994). Conduct disorder patients 20 years later: a personal follow-up study. Acta Psychiatrica Scandinavica, 89, 416-420.

Timmermans, M., van Lier, P. A. C., \& Koot, H. M. (2008). Which forms of child/adolescent externalizing behaviors account for late adolescent risky sexual behavior and substance use? Journal of Child Psychology and Psychiatry, 49, 386-394.

Tremblay, R. E., \& Japel, C. (2003). Prevention during pregnancy, infancy, and the preschool years. In D. P. Farrington \& J. W. Coid (Eds.), Early prevention of adult antisocial behaviour (pp. 205242). Cambridge: Cambridge University Press.

Van Meurs, I., Reef, J., Verhulst, F., \& van der Ende, J. (2009). Intergenerational transmission of child problem behaviors: a longitudinal, population-based study. Journal of the American Academy of Child and Adolescent Psychiatry, 48, 138145.

van Westerlaak, J. H., Kropman, J. A., \& Collaris, J. W. M. (1975). Beroepenklapper (Manual for occupational level). Nijmegen: Instituut voor Sociologie.

Verhulst, F. C., Akkerhuis, G. W., \& Althaus, M. (1985). Mental health in Dutch children (I). A cross-cultural comparison. Acta Psychiatrica Scandinavica, Supplementum, 323, 1-108.

Verhulst, F. C., van der Ende, J., \& Koot, J. M. (1996). Handleiding voor de CBCL/4-18 (manual for the CBCL/4-18). Rotterdam: Erasmus University/Department of Child and Adolescent Psychiatry, Sophia Children's Hospital Akamedish Ziekenhuis Rotterdam/ Erasmus Universiteit Rotterdam.

Washburn, J. J., Gregory Romero, E., Welty, L. J., Abram, K. M., Teplin, L. A., McClelland, G. M., et al. (2007). Development of antisocial personality disorder in detained youths: the predictive value of mental disorders. Journal of Consulting and Clinical Psychology, 75, 221-231. 
Westermeyer, J., \& Thuras, P. (2005). Associations of antisocial personality disorder and substance disorder morbidity in a clinical sample. American Journal of Drug and Alcohol Abuse, 31, 93-110.

Whittinger, N. S., Langley, K., Fowler, T. A., Thomas, H. V., \& Thapar, A. (2007). Clinical precursors of adolescent conduct disorder in children with attention-deficit/hyperactivity disorder.
Journal of the American Academy of Child and Adolescent Psychiatry, 46, 179-187.

Willcutt, E. G., Pennington, B. E., Chhabildas, N. A., Friedman, M. C., \& Alexander, J. (1999). Psychiatric comorbidity associated with DSMIV ADHD in a nonreferred sample of twins. Journal of the American Academy of Child and Adolescent Psychiatry, 38, 1355-1362. 